\title{
MedChemComm
}

CORRECTION

View Article Online

View Journal | View Issue

\section{Correction: Development of highly active anti- Pneumocystis bisbenzamidines: insight into the influence of selected substituents on the in vitro activity}

Cite this: Med. Chem. Commun., $2017,8,2164$

\author{
D. Maciejewska, ${ }^{\star a}$ J. Żabiński, ${ }^{a}$ M. Rezler, ${ }^{a}$ P. Kaźmierczak, ${ }^{a}$ M. S. Collins, ${ }^{\text {bc }}$ \\ L. Ficker ${ }^{\mathrm{bc}}$ and M. T. Cushion ${ }^{\star b c}$
}

DOI: $10.1039 / c 7 m d 90042 b$

Correction for 'Development of highly active anti-Pneumocystis bisbenzamidines: insight into the influence of selected substituents on the in vitro activity' by D. Maciejewska et al., Med. Chem. Commun., 2017, 8,

rsc.li/medchemcomm 2003-2011.

The authors regret that on page 7 of their article the name for compound 13 contains an error. The correct name for 13 is: 1,5bis(4-amidino-2-nitrophenoxy)-3-oxapentane dihydrochloride (with -2- instead of -3-nitrophenoxy).

The Royal Society of Chemistry apologises for these errors and any consequent inconvenience to authors and readers.

\footnotetext{
${ }^{a}$ Department of Organic Chemistry, Faculty of Pharmacy, Medical University of Warsaw, Banacha 1 Street, 02-097 Warsaw, Poland. E-mail: dmaciejewska@wum.edu.pl

${ }^{b}$ Division of Infectious Diseases, Department of Internal Medicine, University of Cincinnati College of Medicine, 231 Albert Sabin Way, Cincinnati, OH 45267, USA.

E-mail: cushionmt@ucmail.uc.edu

${ }^{c}$ Cincinnati Veterans Affairs Medical Center, 3200 Vine Street, Cincinnati, OH 45220, USA
} 